\title{
Simplified Modelling of Tandem Cold Rolling
}

\author{
K. Slimani ${ }^{*, * *}$, M. Zaaf*, and H. Bendjama ${ }^{* *}$ \\ "Badji Mokhtar University, \\ Faculty of Engineering Sciences, \\ Laboratory of Metal Materials Forming ( LMF2M), \\ B.P. 12, 23000 Annaba, Algeria \\ ${ }^{* * *}$ Research Center in Industrial Technologies CRTI, \\ P.O.Box 64, Cheraga 16014 Algiers, Algeria
}

In this paper, a calculation technique for solving the problem of regulating interstand tension in a tandem cold rolling is proposed. Based on the slices' method, the proposed technique develops a computational model for a single stand, and then generalizes it for five stands. The effectiveness of this technique is evaluated using experimental data acquired from tandem rolling mill of IMETAL steel complex of El-Hadjar-Algeria. By taking into account the elasticity of the rolls and using Newton's method, the developed model can be used to calculate successfully the tensions' correction of the five stands. Compared with the LAM3 software, the obtained results indicated that the proposed technique is effective and can be used to produce better performance of tandem cold rolling.

Key words: modelling, tandem cold rolling, slices' method, elasticity, Newton's method.

Запропоновано методику розрахунку для вирішення задачі регуулювання натягу між клітями у тандемному холодному вальцюванні. На основі методи зрізів дана методика розвиває обчислювальний модель для однієї кліті, а потім узагальнює його для п'ятьох клітей. Ефективність цієї методики оцінюється при використанні експериментальних даних, одержаних на тандемному прокатному стані комплексу IMETAL Steel El-HadjarAlgeria. Беручи до уваги пружність вальців і використовуючи Ньютонову

Corresponding author: Kheireddine Slimani

E-mail: khairo23s@gmail.com

Citation: K. Slimani, M. Zaaf, and H. Bendjama, Simplified Modelling of Tandem Cold Rolling, Metallofiz. Noveishie Tekhnol., 40, No. 11: 1509-1520 (2018), DOI: $10.15407 /$ mfint.40.11.1509. 
методу, розроблений модель може бути успішно застосованим при обчисленні натягу для п'ятьох клітей. У порівнянні з програмним забезпеченням LAM3 одержані результати показали, що запропонована методика є ефективною і може бути використаною для підвищення продуктивности тандемного холодного вальцювання.

Ключові слова: моделювання, тандемне холодне вальцювання, метода зрізів, пружність, Ньютонова метода.

Предложена методика расчёта для решения задачи регулирования натяжения между клетями в тандемной холодной прокатке (слитков с одновременным манипулированием). На основе метода срезов данная методика развивает вычислительную модель для одной клети, а затем обобщает её для пяти клетей. Эффективность этой методики оценивается при использовании экспериментальных данных, полученных на тандемном прокатном стане комплекса IMETAL Steel El-Hadjar-Algeria. Принимая во внимание упругость вальцов и используя метод Ньютона, разработанная модель может быть успешно применена при вычислении натяжения для пяти клетей. По сравнению с программным обеспечением LAM3 полученные результаты показали, что предложенная методика эффективна и может быть использована для повышения производительности тандемной холодной прокатки.

Ключевые слова: моделирование, тандемная холодная прокатка, метод срезов, упругость, метод Ньютона.

(Received February 12, 2018; last version - October 9, 2018)

\section{INTRODUCTION}

Rolling mill process plays an important role in assuring high performance, safety and reliability in steel industry. A typical rolling mill consists of a number of rolling stands aligned in line. Its purpose is to convert slabs of metal into a strip of metal of desired dimensions. However, interstand tension control remains a problem due to strong interactions of rolling stands. So, the assurance of a high product quality provides the challenge for technical innovations in modelling, automation and control.

In fact, tandem cold rolling is a highly complex, nonlinear and multivariable process because it allows a large coil to be rolled into multiple stands, which makes its control a major challenge for engineering. Many researchers have paid great attention to produce an acceptable product by proposed basic controllers [1-3]. Other works have also been proposed to offer improvement and robustness to disturbance of the process $[4,5]$.

The modelling of a rolling process can be performed for various purposes. Various models have been studied and developed to predict a rolling torque, force, stresses and speeds in order to size the stands and 
adjust the roll gap for optimal rolling operation [6, 7]. The preliminary knowledge of the mechanical rolling properties and quantities is necessary to ensure the optimal energy consumption. Actually, the Finite Element Method (FEM) is widely used in this field; great progress has been made to develop efficient models to study the propagation, i.e., the enlargement of the hot-rolled strip and the edge shape to achieve an optimized pass design [8-10]. Unfortunately, the models based on FEM require a high computation time and powerful machines, which makes it not advisable for the industrialists who mainly look for efficient and fast online models to pilot their operations. To overcome this difficulty, the slices method is considered. It is an important and efficient method used for cold rolling of thin sheets [11-13]. Its applications in cold rolling have been realized to take into account the shear, the elasticity of the band and the elasticity of the rolls [14-18].

The main objective of this work is to develop a model for calculating the stresses of a stand and their effects on the next stand. This model allows correcting the interstand tensions, which represent a serious problem with tandem rolling. Based on the slices method and using Newton's technique, we can develop a model for the five stands of the process. It is shown that the obtained model can be applied effectively for the correction of interstand tensions and obtaining acceptable speeds. By comparing with LAM3, the results demonstrate the effectiveness of the proposed model.

\section{MATERIALS AND METHODS}

\subsection{Tandem Cold Rolling Process}

Tandem cold rolling process consists of a number of rolling stands aligned in line, where the thickness of a steel sheet is reduced by passing it through rolling stands (see Fig. 1). This reduction caused by a

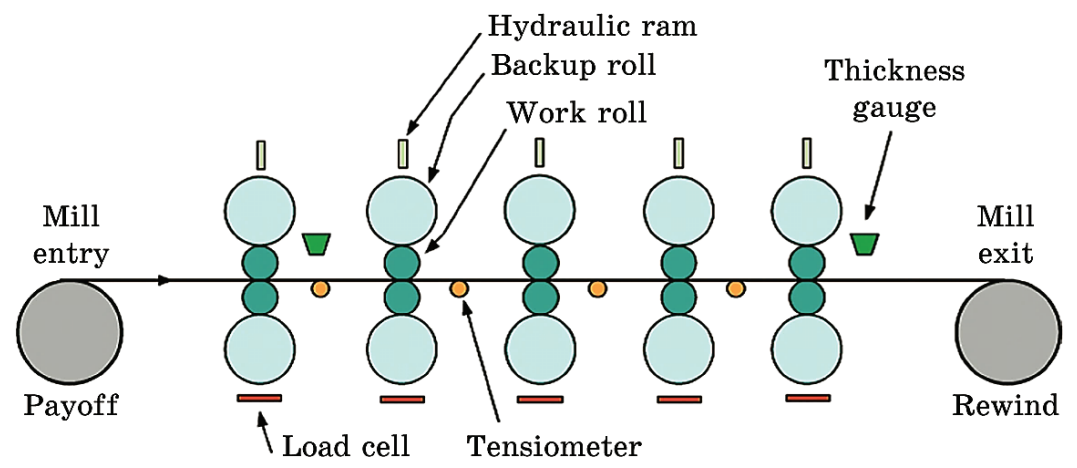

Fig. 1. Typical five stand tandem cold mill [2]. 
very large compression force between the working roll and the sheet, enlarges the strip. There are different types of parameters to be acquired, with reliable instrumentation in tough operating conditions such as: the rolling force, the interstand tension, the strip thickness, and the speeds $[4,5]$.

The speed of a rolled strip leaving a stand $N$ must be identical to the entry speed of the stand $N+1$. If these two speeds differ, a longitudinal force, generally called interstand tension, will result inside the rolled strip can introduce variations in the thickness and/or the width of the sheet, thus deteriorating the product quality.

To improve the efficiency and the quality of the process operation, we have developed an efficient model that allows us to control the interstand tensions and thus correct the rotation speeds.

\subsection{Modelling Method}

The proposed model is based on the slices method. Under MATLAB environment, this method is computed taking into account the elasticity of the rolls. In the following, we calculate, respectively, the mathematical models of one stand, five stands, and the corresponding corrections on the speeds.

In the standard rolling model, the stress and strain only depend on the longitudinal variable $x$. Horizontal equilibrium and the hypothesis $\frac{d h}{d x}<<1, \dot{\varepsilon}_{x z}<<\dot{\varepsilon}_{x x}$ reduce the Karman equation as expressed below [6, 11, 13]:

$$
h \frac{d \sigma_{1}}{d x}=\left(\sigma_{1}-\sigma_{3}\right) \frac{d h}{d x}-\tau,
$$

where $h$ is the half thickness of the slab, $\sigma_{1}, \sigma_{3}$ and $\tau$ denote the longitudinal ( $x$ direction), normal ( $z$ direction) and shear stresses, respectively.

This equilibrium equation has to be supplemented by two constitutive equations:

- for the material behaviour relating $\left(\sigma_{1}-\sigma_{3}\right)$ to $\dot{\varepsilon}_{3}$ (or $\varepsilon_{3}$ in the plastic case);

- for the friction law relating the shear stress $\tau$ to the velocity $v$.

More precisely, the shear stress is assumed small and for a very wide sheet $\varepsilon_{2}=0$, so that

$$
\varepsilon_{i j}=\left[\begin{array}{ccc}
-\varepsilon_{3} & 0 & 0 \\
0 & 0 & 0 \\
0 & 0 & \varepsilon_{3}
\end{array}\right], \sigma_{i j}=\left[\begin{array}{ccc}
\sigma_{1} & 0 & 0 \\
0 & \sigma_{2} & 0 \\
0 & 0 & \sigma_{3}
\end{array}\right], \varepsilon_{3}=-\varepsilon_{1}=\log \frac{h}{h_{0}} .
$$

The viscoplastic or plastic flow rule first gives $\sigma_{2}$ as a function of $\sigma_{1}$ and 
$\sigma_{3}$ from the plane strain condition and then $\left(\sigma_{1}-\sigma_{3}\right)$. Different considerations can be used such as: isotropic or not, plastic or viscoplastic, associated flow rule or not. Similarly, the friction law can be taken as: rateindependent; Coulomb or Tresca, or rate-dependent; Norton-Hoff [6, 7].

Neglecting the hypothesis of rigid stands and assuming that the deformed roll can be locally assimilated to a roll of radius $R^{\prime} \geq R$, where $R^{\prime}$ is the Hitchcock radius, it is calculated by the following formula [13, 14] (J. H. Hitchcock, 1935):

$$
R^{\prime}=R\left\{1+\frac{16\left(1-v^{2}\right)}{\pi b E} \frac{F}{2 h_{e}-2 h_{s}}\right\},
$$

where $E$ is the Young's modulus, $v$ the Poisson's ratio, $F$ the rolling force, $h_{e}$ the input thickness, $h_{s}$ the output thickness and $b$ the width of the band. The rolling force $F$ is calculated by:

$$
F=\int_{-\alpha}^{0} \sigma_{z} R^{\prime} d \theta
$$

The flowchart of the computed model based on slices method is illus-

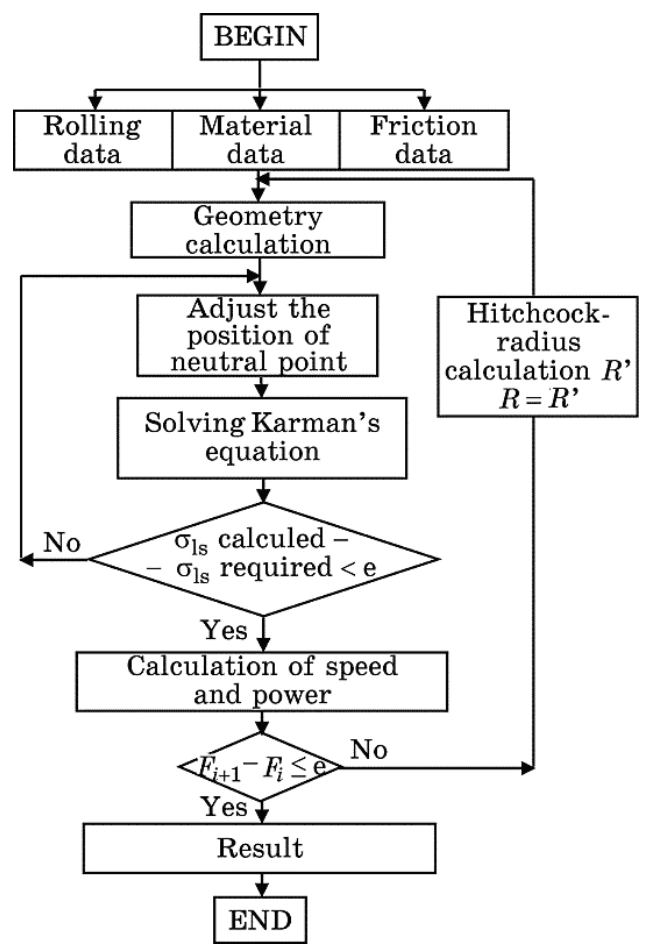

Fig. 2. Framework of the proposed model. 
trated in Fig. 2. We must first determine the neutral point by firing method. For a given position of the neutral point $x_{n}$, the longitudinal stress $\sigma_{1}$ is calculated by integrating the Karman equation using Runge-Kutta method. Then, we adjust the value of $x_{n}$ by the secant method, which appears to coincide with the value $\sigma_{1}$. It results an efficient and fast model that makes it easy to test different hypotheses.

For a tandem rolling process with five stands, which represent our case study, the calculation of each stand involves boundary conditions [11]; the imposed tractions are assumed to be homogeneous on the inlet and outlet sections, i.e., $t_{1}(i)$ and $t_{2}(i)$. Obviously,

$$
t_{2}(i)=t_{1}(i+1) \text { with } i=1,2,3,4,
$$

where $t_{1}$ and $t_{2}$ denote the input and the output tensions.

Therefore, the boundary tensions are imposed as: $\Delta t_{1}(1)=\Delta t_{2}(5)=0$.

Furthermore, the slices method calculates the neutral point of each stand, which makes it possible to obtain the speeds $v_{1}(i)$ and $v_{2}(i)$. To achieve this, we must respect the following condition:

$$
v_{2}(i)=v_{1}(i+1) .
$$

We start an iterative calculation of the interstand (1), (2), which will then be applied to the other interstands. First, we calculate the values of $t_{1}(i)$ and $t_{2}(i)$, and thus, the corresponding corrections $\Delta t$ that can be applied to obtain a near required precision. We assume then obtained, at a certain stage, the approximations $v_{2}(1)$ and $v_{1}(2)$, which are the functions of $t_{1}(2)$ and $t_{2}(2)$. Using Newton's method, we obtain:

$$
\begin{gathered}
v_{2}(1)+\Delta v_{2}(1)=v_{2}(1)+\frac{\partial v_{2}(1)}{\partial t_{1}(1)} \Delta t_{1}(1)+\frac{\partial v_{2}(1)}{\partial t_{2}(1)} \Delta t_{2}(1)=v_{1}(2)+\Delta v_{1}(2), \\
v_{1}(2)+\Delta v_{1}(2)=v_{1}(2)+\frac{\partial v_{1}(2)}{\partial t_{1}(2)} \Delta t_{1}(2)+\frac{\partial v_{1}(2)}{\partial t_{2}(2)} \Delta t_{2}(2), \\
v_{2}(1)+\Delta v_{2}(1)-\left[v_{1}(2)+\Delta v_{1}(2)\right]=0 \\
v_{2}(1)+\frac{\partial v_{2}(1)}{\partial t_{1}(1)} \Delta t_{1}(1)+\frac{\partial v_{2}(1)}{\partial t_{2}(1)} \Delta t_{2}(1)-v_{1}(2)-\frac{\partial v_{1}(2)}{\partial t_{1}(2)} \Delta t_{1}(2)-\frac{\partial v_{1}(2)}{\partial t_{2}(2)} \Delta t_{2}(2) \\
v_{2}(1)-v_{1}(2)=+\frac{\partial v_{2}(1)}{\partial t_{1}(1)} \Delta t_{1}(1)+\frac{\partial v_{2}(1)}{\partial t_{2}(1)} \Delta t_{2}(1)-\frac{\partial v_{1}(2)}{\partial t_{1}(2)} \Delta t_{1}(2)-\frac{\partial v_{1}(2)}{\partial t_{2}(2)} \Delta t_{2}(2)
\end{gathered}
$$

Knowing that $\Delta t_{1}(1)=0$ and $\Delta t_{2}(1)=\Delta t_{1}(2)$, so:

$$
v_{2}(1)-v_{1}(2)=\frac{\partial v_{2}(1)}{\partial t_{2}(1)} \Delta t_{2}(1)-\frac{\partial v_{1}(2)}{\partial t_{1(2)}} \Delta t_{2}(1)-\frac{\partial v_{1}(2)}{\partial t_{2(2)}} \Delta t_{2}(2)
$$




$$
v_{2}(1)-v_{1}(2)=\left[\frac{\partial v_{2}(1)}{\partial t_{2}(1)}-\frac{\partial v_{1}(2)}{\partial t_{1}(2)}\right] \Delta t_{2}(1)-\frac{\partial v_{1}(2)}{\partial t_{2}(2)} \Delta t_{2}(2) .
$$

By using the same calculation steps for the other interstands, (2)(3), (3)-(4), and (4)-(5), we obtain the following equations:

$$
\begin{gathered}
\partial v_{1}(2)-\partial v_{2}(1)=\left[\frac{\partial v_{2}(1)}{\partial t_{2}(1)}-\frac{\partial v_{1}(2)}{\partial t_{1}(2)}\right] \Delta t_{2}(1)-\left[\frac{\partial v_{1}(2)}{\partial t_{2}(2)}\right] \Delta t_{2}(2) \\
\partial v_{1}(3)-\partial v_{2}(2)=\left[\frac{\partial v_{2}(2)}{\partial t_{2}(2)}-\frac{\partial v_{1}(3)}{\partial t_{1}(3)}\right] \Delta t_{2}(2)-\left[\frac{\partial v_{1}(3)}{\partial t_{2}(3)}\right] \Delta t_{2}(3)+\left[\frac{\partial v_{2}(2)}{\partial t_{1}(2)}\right] \Delta t_{2}(1), \\
\partial v_{1}(4)-\partial v_{2}(3)=\left[\frac{\partial v_{2}(3)}{\partial t_{2}(3)}-\frac{\partial v_{1}(4)}{\partial t_{1}(4)}\right] \Delta t_{2}(3)-\left[\frac{\partial v_{1}(4)}{\partial t_{2}(4)}\right] \Delta t_{2}(4)+\left[\frac{\partial v_{2}(3)}{\partial t_{1}(3)}\right] \Delta t_{2}(2), \\
\partial v_{1}(5)-\partial v_{2}(4)=\left[\frac{\partial v_{2}(4)}{\partial t_{2}(4)}-\frac{\partial v_{1}(5)}{\partial t_{1}(5)}\right] \Delta t_{2}(4)-\left[\frac{\partial v_{1}(2)}{\partial t_{2}(2)}\right] \Delta t_{2}(4) .
\end{gathered}
$$

In the matrix form $\Delta t=M^{-1} \Delta v$, the previous equations become:

$$
\begin{aligned}
& \left(\begin{array}{c}
\Delta \mathbf{t}_{2}(2) \\
\Delta \mathbf{t}_{2}(2) \\
\Delta \mathbf{t}_{2}(3) \\
\Delta \mathbf{t}_{2}(4)
\end{array}\right)= \\
& =\left(\begin{array}{cccc}
\frac{\partial \mathbf{v}_{2}(1)}{\partial \mathbf{t}_{2}(\mathbf{1})}-\frac{\partial \mathbf{v}_{1}(2)}{\partial \mathbf{t}_{1}(2)} & -\frac{\partial \mathbf{v}_{1}(2)}{\partial \mathbf{t}_{2}(2)} & 0 & 0 \\
\frac{\partial \mathbf{v}_{2}(2)}{\partial \mathbf{t}_{1}(2)} & \frac{\partial \mathbf{v}_{2}(2)}{\partial \mathbf{t}_{2}(2)}-\frac{\partial \mathbf{v}_{1}(3)}{\partial \mathbf{t}_{1}(3)} & -\frac{\partial \mathbf{v}_{1}(3)}{\partial \mathbf{t}_{2}(3)} & 0 \\
0 & \frac{\partial \mathbf{v}_{2}(3)}{\partial \mathbf{t}_{1}(3)} & \frac{\partial \mathbf{v}_{2}(3)}{\partial \mathbf{t}_{2}(3)}-\frac{\partial \mathbf{v}_{1}(4)}{\partial \mathbf{t}_{1}(4)} & -\frac{\partial \mathbf{v}_{1}(4)}{\partial \mathbf{t}_{1}(4)} \\
0 & 0 & \frac{\partial \mathbf{v}_{1}(4)}{\partial \mathbf{t}_{1}(4)} & \frac{\partial \mathbf{v}_{2}(4)}{\partial \mathbf{t}_{2}(4)}-\frac{\partial \mathbf{v}_{1}(5)}{\partial \mathbf{t}_{1}(5)}
\end{array}\right)^{-1} \times \\
& \times\left(\begin{array}{l}
v_{1}(2)-v_{2}(1) \\
v_{1}(3)-v_{2}(2) \\
v_{1}(4)-v_{2}(3) \\
v_{1}(5)-v_{2}(4)
\end{array}\right) \text {. }
\end{aligned}
$$

The relation between velocity and tension makes it possible to determine the influence coefficients: $\partial v_{1} / \partial t_{1}, \partial v_{2} / \partial t_{1}, \partial v_{1} / \partial t_{2}, \partial v_{2} / \partial t_{2}$, 
that then allows deducing the $\Delta t$ as well as the real tensions $t^{\prime}=t+\Delta t$.

\section{RESULTS AND DISCUSSION}

In this section, the algorithm presented earlier will be demonstrated and discussed. We start with a validation of our single-stand model compared to LAM3 software. LAM3 is a tool used for finite element thermomechanical calculations; it is currently applied by ArcelorMittal researchers to simulate rolling operations. The comparison is made using the data and results presented in [13]. The data set of cold rolling employed are: $h_{e}=1.957 \mathrm{~mm}, h_{s}=1.370, k=0.4, \sigma_{e}=150 \mathrm{MPa}, \sigma_{s}=150$ $\mathrm{MPa}, \sigma_{0}=600 \mathrm{MPa}, R=250 \mathrm{~mm}, \omega=4 \mathrm{rad} / \mathrm{s}$.

Figure 3 shows the calculation of the longitudinal and normal stresses of cold rolling in the elastoplastic case. The obtained results show that the calculated model is reliable compared to LAM3.

After validating the obtained model, testing the model for five stands was established. The data set was collected from the tandem cold rolling of the IMETAL steel complex of El-Hadjar-Algeria. The validation of the proposed model is carried out using a steel coil DX51D (A9M) corresponding to the presumed FePO2G grade.

After determining of an operating point using a typical production program, the rolling mill and strip parameters used in this study are presented in Table 1 .

Exploitation of the experimental data must identify the Hollomon hardening law $\left(\sigma=A \varepsilon^{n}\right)$ [13]. Therefore, it was a question of identifying $A$ and $n$. For each stand, the calculated values are listed in Table 2.
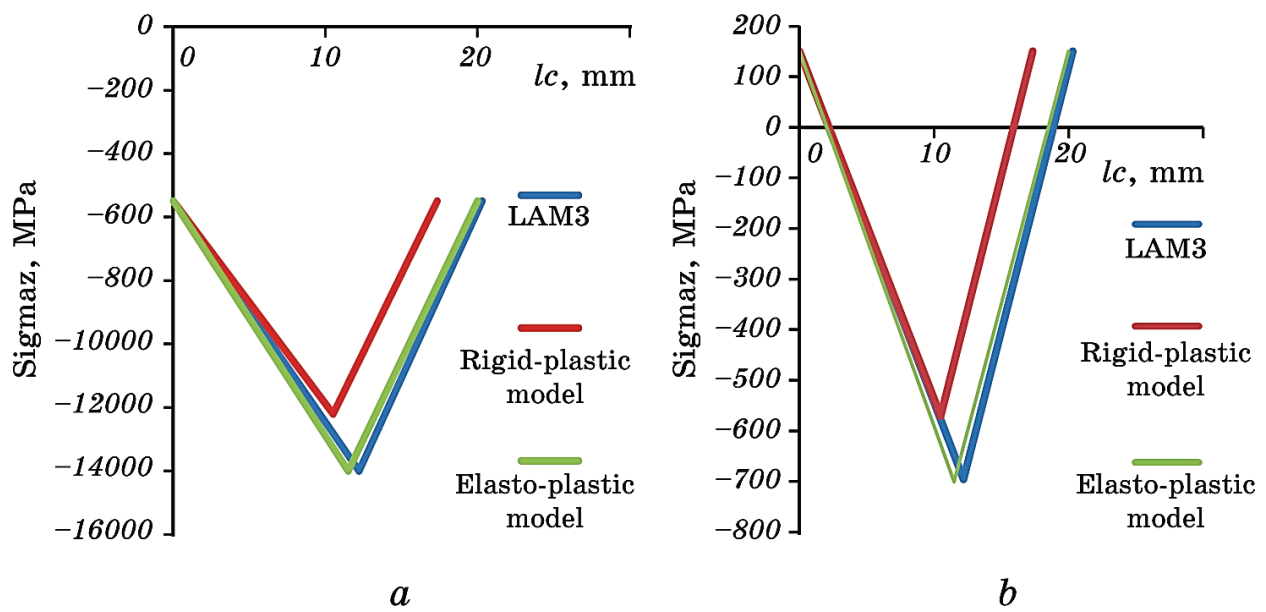

Fig. 3. Stress of cold rolling in the elastoplastic case: $a$-longitudinal, $b-$ normal. 
TABLE 1. Rolling parameters.

\begin{tabular}{ccccccc}
\hline Stand & $h_{\text {input }}, \mathrm{mm}$ & $h_{\text {output }}, \mathrm{mm}$ & $R_{\text {cyl }}, \mathrm{mm}$ & $\Omega, \mathrm{rad} / \mathrm{s}$ & $T_{e}(t f)$ & $T_{s}(t f)$ \\
\hline 1 & 02 & 1.53 & 281 & 30.6 & 30 & 22 \\
2 & 1.53 & 1.07 & 264 & 56.08 & 22 & 19 \\
3 & 1.07 & 0.78 & 270 & 64.07 & 19 & 14 \\
4 & 0.78 & 0.54 & 281 & 70.37 & 14 & 11 \\
5 & 0.54 & 0.37 & 281 & 76.02 & 11 & 9 \\
\hline
\end{tabular}

Figure 4 shows the calculation results of the first stand before the regulation of the tension, the same calculations are repeated for the other stands. The calculated speeds before regulation are presented in Table 3. It is clear that the speed of a rolled strip leaving an earlier stand is not identical to its entry speed into the adjacent downstream stand. Our goal is therefore to determine for each stand, the corresponding tension correction to obtain identical speeds and tensions between the output of a stand and the input of the next stand.

The steps to follow to correct the speeds are:

- build matrix $C=v_{2}-v_{1}$ by the input and output speeds of each stand;

- build matrix $(M)$ by the influence coefficients of each stand;

- replace the new tension $t^{\prime}=t+\Delta t$, where $\Delta t$ is the correction of tensions, $t$ the old tension and $t^{\prime}$ the new tension.

To ensure product quality, we must take into account the following corrections:

$$
\Delta t(\mathrm{MPa})=\left[\begin{array}{c}
41.2402 \\
-64.3154 \\
-238.5046 \\
137.8939
\end{array}\right]
$$

Figure 5 shows the calculation results after tension regulation. It simultaneously gives the evolution of flow constraints, normal, longitudinal and tangential stresses as well as sliding speeds for each stand.

TABLE 2. Hollomon hardening coefficients.

\begin{tabular}{c|c|c|c|c|c}
\hline Stand number & 1 & 2 & 3 & 4 & 5 \\
\hline$A$ & 663.3 & 753.4 & 807.2 & 843.2 & 894.5 \\
$n$ & 0.125 & 0.064 & 0.027 & 0.024 & 0.022 \\
\hline
\end{tabular}



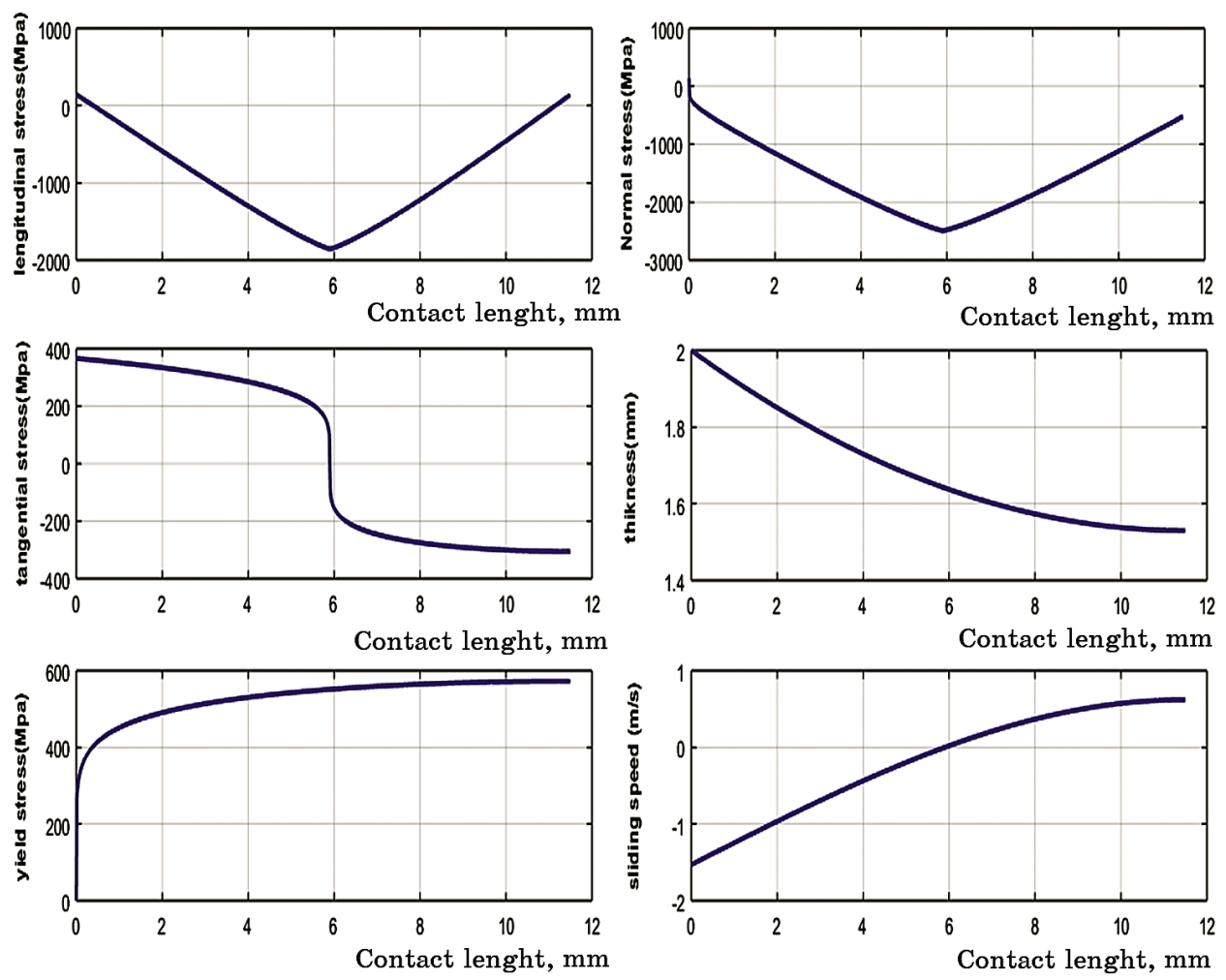

Fig. 4. Calculated parameters in the first stand.

The main notes are:

- the thickness varies from $2 \mathrm{~mm}$ (input of the first stand) to 0.37 $\mathrm{mm}$ (output of the fifth stand);

- for the flow stress, the flow of material is remarkable at the beginning of the reduction at the neutral point because the rolling force reaches its maximum at this point, then becomes almost constant, i.e., the dislocation density reaches its saturation point which is near the neutral point, then a balance is created between restoration and annihilation according to the deformation effect. Until the fifth stand, the curve represents almost perfect plastic behaviour:

TABLE 3. Speeds values before regulation.

\begin{tabular}{c|c|c|c|c|c}
\hline Stand number & 1 & 2 & 3 & 4 & 5 \\
\hline$v_{1}, \mathrm{~m} / \mathrm{s}$ & 7.006 & 11,356 & 13,868 & 15,077 & 19.29 \\
$v_{2}, \mathrm{~m} / \mathrm{s}$ & 9.1511 & 16,237 & 19,024 & 21,777 & 28.15 \\
$v_{n}, \mathrm{~m} / \mathrm{s}$ & 8.531 & 14.805 & 17.298 & 19.7739 & 21.361 \\
\hline
\end{tabular}




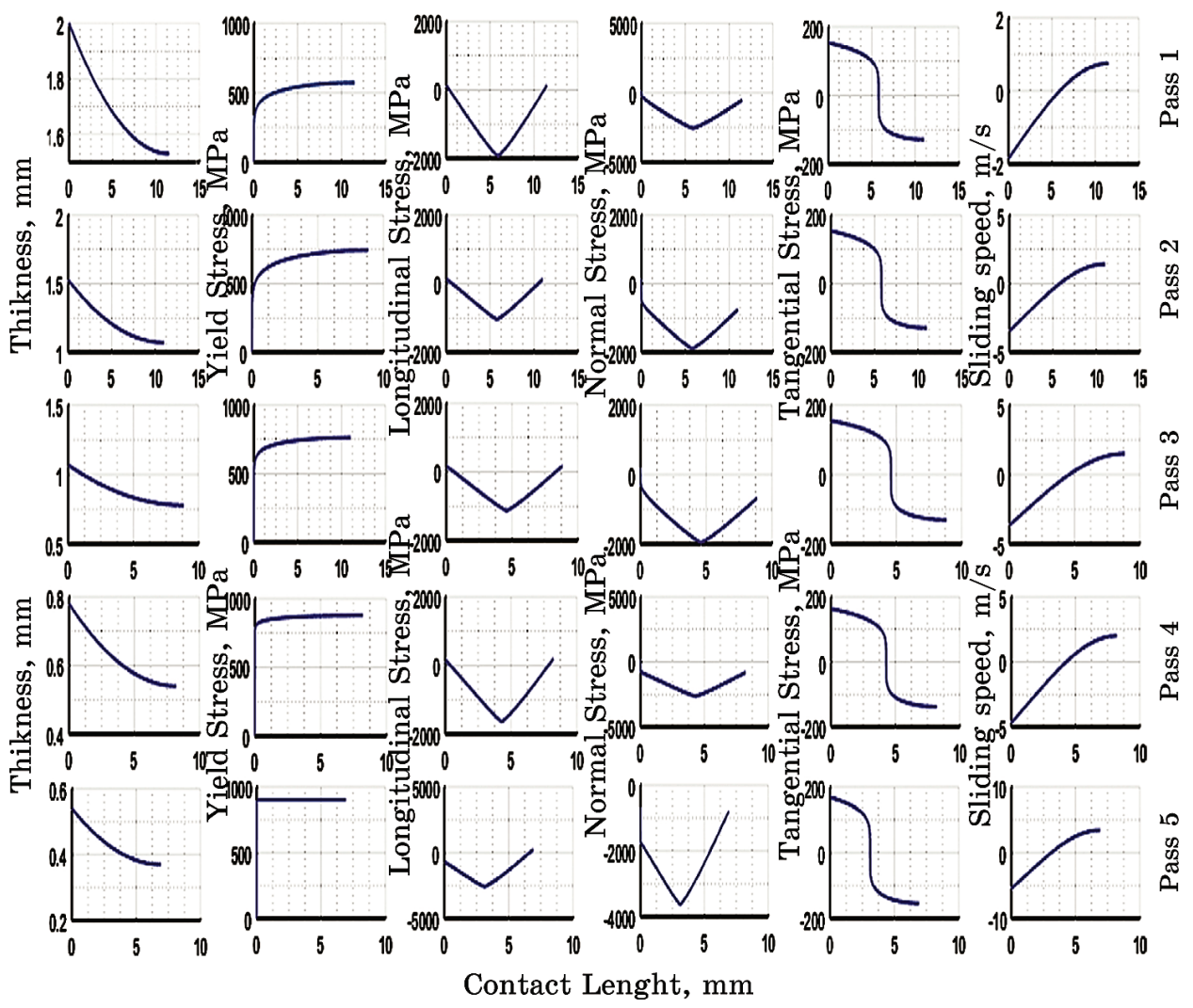

Fig. 5. Calculated parameters for five stands.

- the longitudinal and normal stresses evolve in the same way by forming a hill at the top corresponding to the neutral point $(V g=0)$ where the friction changes direction;

- the friction is calculated by Norton-Hoff law where the coefficients are adjustment factors so that the calculated effort is equal to the measured effort;

- the sliding speed is negative at the neutral point input $(V g=0)$ and changes direction until the output.

From the calculated values of the rolling speeds listed in Table 4, it

TABLE 4. Corrected speeds.

\begin{tabular}{c|c|c|c|c|c}
\hline Stand number & 1 & 2 & 3 & 4 & 5 \\
\hline$v_{1}, \mathrm{~m} / \mathrm{s}$ & 7.9193 & 10.574 & 15.869 & 18.911 & 20.901 \\
$v_{2}, \mathrm{~m} / \mathrm{s}$ & 10.552 & 15.849 & 18.907 & 20.892 & 27.061 \\
\hline
\end{tabular}


is seen clearly that the output speeds of each stand is approximately identical to the input speed of the next stand. So, the calculation speeds obtained by our model show that the refinements proposed make it possible to solve the problem: $v_{2}(i)=v_{1}(i+1)$.

\section{CONCLUSION}

The work presented in this paper is focused on the improvement of the classical simplified models of rolling process. For this purpose, a simplified model that takes into account the plastic deformations of the plates with hardening, the elastic deformation of the rolls, and the regulation of the tensions between the stands has been developed. It is based on the slices' method with the consideration of roll elasticity. It results a simple and effective model that is validated by applications on real data acquired from tandem cold rolling mill of IMETAL El-Hadjar. The obtained model can successfully correct the interstand tensions. Comparing with LAM3, the results of the proposed model have confirmed its reliability that we recommend it to manufacturers.

\section{REFERENCES}

1. C. F. Bryant, Automation of Tandem Mills (London, U.K.: British Iron and Steel Institute: 1973).

2. A. J. Carlton and R. G. Conway, Iron Steel Eng., 69, No. 6: 17 (1992).

3. P. Duval, J. C. Parks, and G. Fellus, Iron Steel Eng., 68, No. 11: 46 (1991).

4. E. J. M. Geddes, Tandem Cold Rolling and Robust Multivariable Control (Ph.D. Disser.) (Control Syst. Res., Dept. Elect. Eng., Univ. Leicester, U.K.: 1998).

5. I. Hoshino et al., Automatica, 24, No. 6: 741 (1988).

6. Von Kármán and T. Beitragzur, Z.Angew. Math. Mech., 5: 139 (1925).

7. $\quad$ E. Orowan, Proc. Instn. Mech.Eng., 150: 140 (1943).

8. K. Mori and K. Osakada, Int.J.Mech.Sci., 26, Nos. 9-10: 515 (1984).

9. H. J. Huisman and J. Huétink, J. Mech. Working Technol., 11: 333 (1985).

10. J.-L. Chenot, P. Montmitonnet, A. Bern, and C. Bertrand-Corsini, Comput. Meth.Appl.Mech.Eng., 92, No. 2: 245 (1991).

11. P. Montmitonnet, Laminage a Froid: Modélisation M616 (Paris: 2000).

12. P. Montmitonnet, Laminage-Analyse Thermomécanique $2 D$ et Application aux Produit Plats M3066V2 (Juin, 2016).

13. Huy Le Dang, Modélisation Simplifiée des Processus de Laminage (2014).

14. E. Orowan, Proc. Instn. Mech.Eng., 150: 140 (1943).

15. D. R. Bland and H. Ford, J. Iron Steel Inst., 171: 245 (1952).

16. P. Cosse and M. Economopoulos, CNRM, 17: 15 (1968).

17. D. Jortner, J. F. Osterle, and C. F. Zorowski, Int. J. Mech.Sci., 2: 179 (1960).

18. A. Hacquin, P. Montmitonnet, and J.-Ph. Guillerault, Eur.J.Mech. A (Solids), 1: 79 (1998). 